\title{
Retrospective Analysis on the Efficacy, Safety and Treatment Failure Group of Sitagliptin for Mean 10-Month Duration
}

Won Jun Kim, Cheol-Young Park, Eun Haeng Jeong, Jeong Youn Seo, Ji Soo Seol, Se Eun Park, Eun Jung Rhee, Won Young Lee, Ki Won Oh, Sung Woo Park, Sun Woo Kim

Department of Endocrinology and Metabolism, Kangbuk Samsung Hospital, Sungkyunkwan University School of Medicine, Seoul, Korea

Background: To investigate the clinical results of sitagliptin (SITA) and the characteristics of the treatment failure group or of low responders to SITA.

Methods: A retrospective study of type 2 diabetic patients reviewed 99 cases, including 12 treatment failure cases, who stopped SITA because of worsening patients' condition, and 87 cases, who continued treatment over five visits (total $9.9 \pm 10.1$ months) after receiving the prescription of SITA from December 2008 to June 2009. Subjects were classified as five groups administered SITA as an initial combination with metformin (MET), add-on to metformin or sulfonylurea, and switching from sulfonylurea or thiazolidinedione. The changes in $\mathrm{HbAlc}$ level from the first to last visit $(\triangle \mathrm{HbAlc})$ in treatment maintenance group were subanalyzed.

Results: The $\mathrm{HbAlc}$ level was significantly reduced in four groups, including initial coadministration of SITA with metformin $(\triangle \mathrm{HbAlc}=-1.1 \%, P<0.001)$, add-on to MET $(\triangle \mathrm{HbAlc}=-0.6 \%, P=0.017)$, add-on to sulfonylurea $(\triangle \mathrm{HbAlc}=-0.5 \%, P<0.001)$, and switching from thiazolidinedione $(\triangle \mathrm{HbAlc}=-0.3 \%, P=0.013)$. SITA was noninferior to sulfonlyurea $(\triangle \mathrm{HbA} 1 \mathrm{c}=-0.2 \%$, $P=0.63)$. There was no significant adverse effect. The treatment failure group had a longer diabeties duration $(P=0.008)$, higher HbAlc $(P=0.001)$ and fasting plasma glucose $(P=0.003)$ compared to the maintenance group. Subanalysis on the tertiles of $\triangle \mathrm{HbA} 1 \mathrm{c}$ showed that low-response to SITA (tertile 1$)$ was associated with a longer diabetes duration $(P=0.009)$ and lower HbA1c $(P<0.001)$.

Conclusion: SITA was effective and safe for use in Korean type 2 diabetic patients. However, its clinical responses and long-term benefit-harm profile is yet to be established.

Keywords: Diabetes mellitus, type 2; Sitagliptin; Treatment outcome

\section{INTRODUCTION}

The prevalence of type 2 diabetes, which is caused by mechanisms such as insulin secretory defect failure and insulin resistance, is rapidly increasing worldwide. To prevent complications in the early stages of type 2 diabetes occupying $90 \%$ to $95 \%$ of South Korean diabetic patients [1], a thorough blood glucose management should be established [2]. According to the American Diabetes Association (ADA) guidelines and the European Association of the Study of Diabetes, initial therapy should involve lifestyle changes and metformin (MET) treatment. However, because of the progressive nature of the disease, combination therapy consisting of two or more drugs or insulin therapy is typically necessary over time [3].
Corresponding author: Cheol-Young Park

Department of Endocrinology and Metabolism, Kangbuk Samsung Hospital, Sungkyunkwan University School of Medicine, 108 Pyeong-dong, Jongno-gu, Seoul 110-746, Korea

E-mail: cydoctor@chol.com

Received: Apr. 27, 2010; Accepted: Dec. 23, 2010
This is an Open Access article distributed under the terms of the Creative Commons Attribution Non-Commercial License (http://creativecommons.org/licenses/by-nc/3.0/) which permits unrestricted non-commercial use, distribution, and reproduction in any medium, provided the original work is properly cited.

Copyright (c) 2011 Korean Diabetes Association

http://e-dmj.org 
The main incretin hormones glucagon-like peptide-1 (GLP1) and glucose-dependent insulinotropic polypeptide (GIP) stimulate insulin synthesis and secretion in the $\beta$-cells of the pancreas when blood glucose levels are high. The use of a glucagon suppressing hormone from $\alpha$-cells [4] has resulted in significant improvements of differentiation and proliferation of $\beta$-cells and inhibition of apoptosis in animal model and human islets [5,6]. In type 2 diabetes patients, GLP-1 secretion and GIP function decrease, however, these incretin hormones can be increased by inhibition of incretin-disabling enzyme dipeptidyl peptidase IV (DPP-IV) [7-9].

Sitagliptin (SITA), an oral DPP-IV inhibitor has been proven valid and low risk of side effects, such as hypoglycemia and weight gain in the treatment of type 2 diabetes. Dhillon [10] has reviewed that the addition of SITA to ongoing treatment therapies resulted in significant improvements to HbAlc. Moreover, the report showed that SITA was noninferior to glipizide and generally did not differ from rosiglitazone. SITA can improved $\mathrm{HbAlc}$ without weight gain and rarely results in hypoglycemia except for coadminstration with sulfonylurea (SU) or insulin.

SITA was first used as a DPP-IV inhibitor in South Korea in early 2008, and the prevalence of SITA prescription in South Korea is increasing. However, results from Korean subjects are limited and so more data and research are required. The present study was performed in tertiary hospitals, and we investigated the clinical characteristics of type 2 diabetic patients who received SITA.

\section{METHODS}

\section{Setting and patients}

A retrospective study was conducted for patients starting SITA therapy for type 2 diabetes between December 2008 and June 2009, who attended the outpatient clinic at intervals of two to three months for a total of five visits.

The treatment maintenance group was defined as patients who continued a daily dose of $100 \mathrm{mg}$ SITA during follow-up periods, and the treatment failure group was defined as patients who had discontinued SITA treatment because of increasing HbAlc level above 7\% and worsening patients' condition. Among a total of 99 patients, 87 belonged to the treatment maintenance group and 12 were included in the treatment failure group. Exclusion criteria was switch from more than two different kinds of diabetes medications, voluntary discontinuation of SITA treatment, and follow-up loss. The cases of SITA switched from or added-on to previous medications such as meglitinide, $\alpha$-glucosidase inhibitor or insulin were rare, so they were also excluded.

Patients in the treatment maintenance group were subdivided into five groups: an initial coadministration of SITA with MET group, add-on to MET or SU groups, switch from SU or thiazolidinedione (TZD) groups.

Additionally, for the 87 patients in the treatment maintenance group the changes in $\mathrm{HbAlc}$ level from the first to last visit (HbAlc at visit $1-\mathrm{HbAlc}$ at visit $5, \Delta \mathrm{HbAlc}$ ) were used to divide into three subgroups. The first tertile group had a low response, and the third tertile group had a good response, so they were comparatively analyzed. SITA prescription beyond coverage of medical insurance was paid privately after the consent of the patients.

\section{Explanatory variables and outcome measures}

Fasting plasma glucose levels (FPG) and $\mathrm{HbA1c}$ were measured in the outpatient clinic. Blood glucose was measured using the glucose oxidase method (CX3 DELTA; Beckman, Brea, CA, USA); HbA1c was measured using high-performance liquid chromatography (Bio-Rad, Richmond, CA, USA); and insulin and C-peptide levels were measured using a gamma counter (Dream Gamma-10; ShinJin Medics Co., Seoul, Korea). Body mass index (BMI) was surveyed within the first year of SITA administration, and outpatient records or prescriptions including personal history, drugs taken, and side effects were examined.

\section{Statistical analysis}

All measurements were expressed as mean \pm standard deviation (SD) or as median (25\% confidence interval [CI], 75\% $\mathrm{CI}$. For discontinuous variables, a chi-square analysis was used. For continuous variables, $\triangle \mathrm{HbAlc}$ and the changes in the FPG $(\triangle \mathrm{FPG})$ during follow-up periods were examined using the Wilcoxon Signed Rank test because the KolmogorovSmirnov test did not demonstrate normality; the Mann-Whitney test was used for the comparative analysis between the treatment failure and maintenance group. For subanalysis, the Kruskal-Wallis test was used to compare tertiles of $\triangle \mathrm{HbA1c}$ in the treatment maintenance group. The SPSS for Windows, version 17.0, was used for statistical analysis (SPSS Inc., Chicago, IL, USA), and $P$ values less than 0.05 were considered to be statistically significant. 


\section{RESULTS}

\section{Baseline characteristics}

During the study period, 160 patients were newly prescribed with SITA. Over five visits to the outpatient clinic, 87 patients maintained the type and amount of antidiabetic medication and their mean follow-up period was $9.9 \pm 10.1$ months. We discontinued administration of SITA in the 12 members in the treatment failure group with deteriorating blood glucose. Of the 99 total participants, the mean age was $53.9 \pm 12.0$, women were $63(64 \%)$, and the duration of diabetes was $4.5 \pm 4.9$ years.

The initial coadministration of SITA and MET group included 21 patients, the add-on SITA to MET group had 18 patients, the add-on SITA to SU group had 12 patients, the group switched from SU had 22 patients, and the group switched from TZD had 14 patients. MET was prescribed to $86 \%$ to $100 \%$ of patients in each group. The age, diabetes duration, HbAlc,
FPG, fasting insulin level, fasting C-peptide level, and BMI were expressed as mean \pm SD or median $(25 \% \mathrm{CI}, 75 \% \mathrm{CI})$ and gender, history of taking antihypertensive and antihyperlipidemic medications were examined as number and percentage (Table 1).

\section{$\triangle \mathrm{HbA} 1 \mathrm{c}$ and $\triangle \mathrm{FPG}$ before and after SITA administration}

The groups that had statistically significant reductions in HbAlc level between visit 1 and visit 5 ( $\triangle \mathrm{HbAlc}$ ) included the initial coadministration of SITA and MET group $(\triangle \mathrm{HbA} 1 \mathrm{c}=-1.1 \%, P<0.001)$, the add-on SITA to SU group $(\triangle \mathrm{HbA} 1 \mathrm{c}=-0.5 \%, P<0.001)$, the add-on SITA to MET group $(\triangle \mathrm{HbA} 1 \mathrm{c}=-0.6 \%, P=0.017)$, and the group switched from TZD $(\triangle \mathrm{HbA} 1 \mathrm{c}=-0.3 \%, P=0.013)$. While HbA1c levels decreased significantly at visit 2 , those from visit 2 through visit 5 were not significantly different. The mean doses of the group switched from SU were $1.8 \mathrm{mg}$ in the case of glimepiride

Table 1. Baseline characteristics of subgroups classified by medication regimen

\begin{tabular}{|c|c|c|c|c|c|c|}
\hline Characteristic (at visit 1) & $\begin{array}{l}\text { SITA }+\mathrm{MET}^{\mathrm{a}} \\
\quad(n=21)\end{array}$ & $\begin{array}{l}\text { Adding on MET } \\
\quad(n=18)\end{array}$ & $\begin{array}{l}\text { Adding on SU } \\
\quad(n=12)\end{array}$ & $\begin{array}{l}\text { Switching from SU } \\
\qquad(n=22)\end{array}$ & $\begin{array}{l}\text { Switching from } \\
\text { TZD }(n=14)\end{array}$ & Total $(n=87)$ \\
\hline \multirow[t]{2}{*}{ Age, yr } & $53.4 \pm 9.7$ & $49.8 \pm 10.7$ & $55.8 \pm 10.4$ & $58.8 \pm 13.5$ & $49.8 \pm 10.7$ & $54.1 \pm 11.5$ \\
\hline & $53.0(47.5,61.0)$ & $49.0(44.8,56.3)$ & $56.0(46.8,64.8)$ & $60.0(55.0,65.5)$ & $52.5(40.8,59.5)$ & \\
\hline \multirow[t]{2}{*}{ Duration of T2DM, yr } & $1.6 \pm 2.0$ & $3.9 \pm 2.8$ & $7.9 \pm 4.5$ & $3.2 \pm 2.2$ & $3.7 \pm 2.1$ & $3.7 \pm 3.2$ \\
\hline & $0.5(0.1,2.5)$ & $3.3(1.5,5.0)$ & $7.5(3.5,1.3)$ & $2.9(1.3,4.4)$ & $3.3(2.3,5.5)$ & \\
\hline Females, $n(\%)$ & $13(62)$ & $15(83)$ & $9(75)$ & $10(46)$ & $9(64)$ & $56(64.4)$ \\
\hline \multirow[t]{2}{*}{$\mathrm{BMI}, \mathrm{kg} / \mathrm{m}^{2}$} & $26.6 \pm 3.4$ & $24.3 \pm 2.5$ & $24.0 \pm 4.2$ & $26.0 \pm 3.5$ & $27.4 \pm 3.3$ & $25.8 \pm 3.4$ \\
\hline & $25.2(24.2,29.3)$ & $24.4(22.0,26.9)$ & $25.7(19.8,27.4)$ & $25.2(22.7,28.1)$ & $26.5(24.6,30.2)$ & \\
\hline \multirow[t]{2}{*}{ HbAlc, $\%$} & $7.3 \pm 1.1$ & $7.1 \pm 0.8$ & $7.7 \pm 0.6$ & $6.8 \pm 0.6$ & $7.3 \pm 1.1$ & $7.2 \pm 0.9$ \\
\hline & $7.0(6.6,7.8)$ & $7.2(6.4,7.6)$ & $7.6(7.2,8.2)$ & $6.7(6.3,7.1)$ & $7.0(6.5,7.7)$ & \\
\hline \multirow[t]{2}{*}{$\mathrm{FPG}, \mathrm{mg} / \mathrm{dL}$} & $158.5 \pm 24.3$ & $136.7 \pm 25.4$ & $152.1 \pm 21.1$ & $127.9 \pm 21.8$ & $152.2 \pm 31.2$ & $144.3 \pm 27.3$ \\
\hline & $156(138,178)$ & $137(114,152)$ & $151(130,175)$ & $122(118,148)$ & $147(131,172)$ & \\
\hline $\begin{array}{l}\text { Anti-hypertensive } \\
\text { agent, } n(\%)\end{array}$ & $9(42.9)$ & $6(33.3)$ & $9(75.0)$ & $10(45.5)$ & $7(50.0)$ & $41(47.0)$ \\
\hline Anti-lipid agent, $n(\%)$ & $7(33)$ & $11(61.1)$ & $9(75.0)$ & $13(59.1)$ & $11(78.6)$ & $55(63.2)$ \\
\hline MET agent, $n(\%)$ & $21(100)$ & $18(100)$ & $11(92)$ & $20(91)$ & $13(86)$ & $82(94.3)$ \\
\hline \multirow[t]{2}{*}{ Fasting insulin, $\mu \mathrm{IU} / \mathrm{mL}$} & $13.3 \pm 6.0$ & $10.4 \pm 3.5$ & $8.5 \pm 5.0$ & $11.9 \pm 3.9$ & $11.3 \pm 2.2$ & $11.8 \pm 4.6$ \\
\hline & $12.5(7.8,18.0)$ & $9.1(8.0,11.7)$ & $8.5(4.9,14.0)$ & $11.9(8.7,14.6)$ & $11.8(9.6,12.9)$ & \\
\hline \multirow{2}{*}{$\begin{array}{l}\text { Fasting C-peptide, } \\
\mathrm{ng} / \mathrm{mL}\end{array}$} & $4.0 \pm 1.6$ & $2.4 \pm 2.5$ & $2.1 \pm 1.0$ & $3.2 \pm 0.8$ & $3.1 \pm 0.8$ & $3.3 \pm 1.3$ \\
\hline & $3.4(2.8,5.5)$ & $2.4(2.1,3.3)$ & $2.1(1.4,3.1)$ & $3.3(2.8,3.7)$ & $2.9(2.3,3.9)$ & \\
\hline
\end{tabular}

Data are presented as mean \pm standard deviation and median (25\% confidence interval [CI], 75\% CI) except female, using anti-hypertensive agent and anti-lipid agent and metformin agent $(n[\%])$.

SITA, sitagliptin; MET, metformin; SU, Sulfonylurea; TZD, thiazolidinedione; T2DM, type 2 diabetes mellitus; BMI, body mass index; FPG, fasting plasma glucose.

${ }^{a}$ Denotes initial combination of sitagliptin with metformin. 
Table 2. Efficacy of subgroups on HbAlc and fasting plasma glucose change ( $\Delta \mathrm{HbA} 1 \mathrm{c}$ and $\Delta \mathrm{FPG})$ by sitagliptin from visit 1 to visit 5

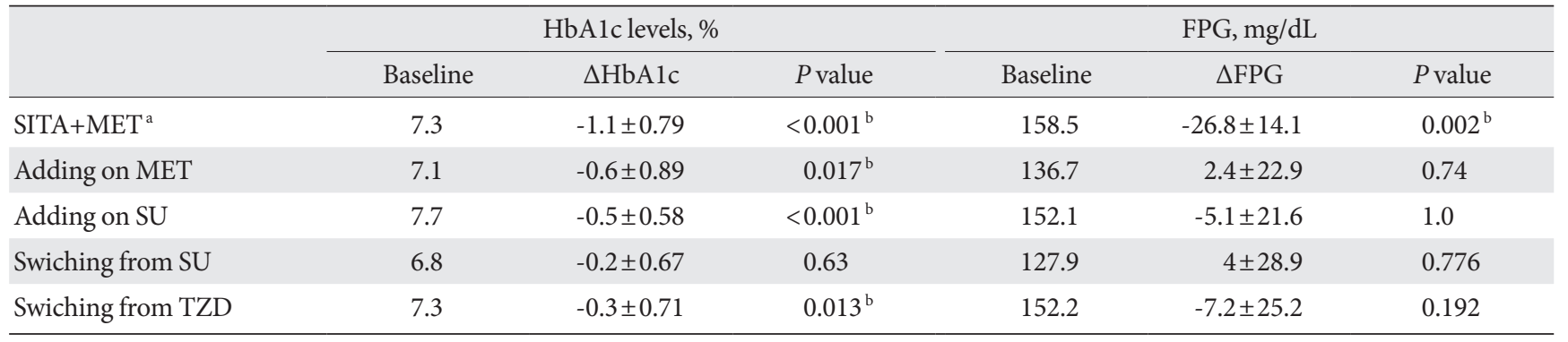

FPG, fasting plasma glucose; SITA, sitagliptin; MET, metformin; SU, Sulfonylurea; TZD, thiazolidinedione.

${ }^{a}$ Denotes initial combination of sitagliptin with metformin, ${ }^{b}$ Statistical significances were tested by Wilcoxon Signed Rank test.

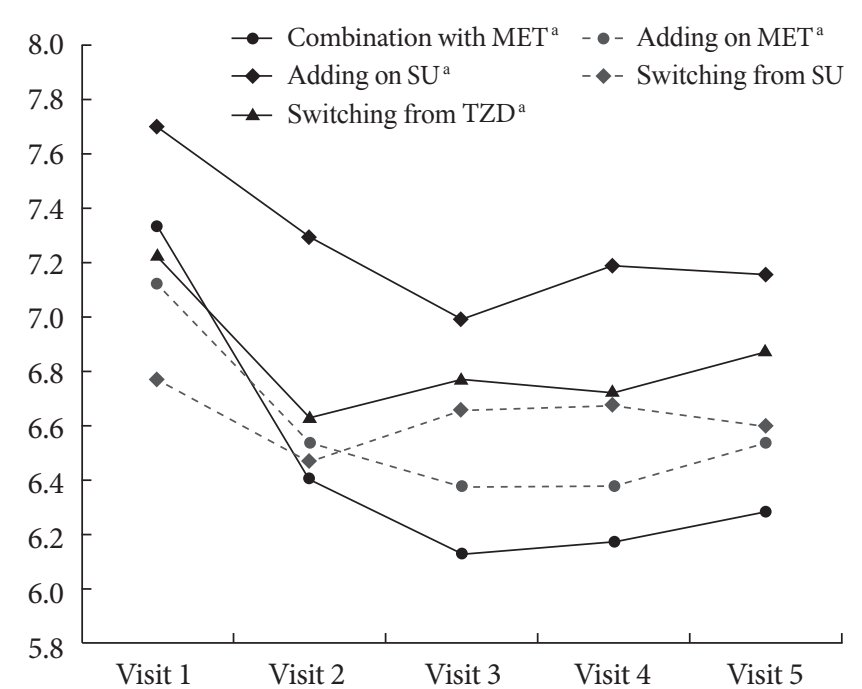

Fig. 1. HbA1c change over time. MET, metformin; SU, Sulfonylurea; TZD, thiazolidinedione. ${ }^{a}$ Denotes significant reduction by according to the Wilcoxon Signed Rank test.

$(n=18)$ and $30 \mathrm{mg}$ in the case of gliclazide (modified- release form; MR) $(n=4)$, but no statistically significant reductions were observed $(\triangle \mathrm{HbA} 1 \mathrm{c}=-0.2 \%, P=0.63)$ (Table 2 , Fig. 1$)$.

The statistically significant reduction in FPG between visit 1 and visit 5 ( $\triangle \mathrm{FPG}$ ) was only observed in the initial coadministration of SITA and MET group $(\triangle \mathrm{FPG}=-26.8 \mathrm{mg} / \mathrm{dL}, P=$ $0.002)$, and there were no significant changes in the group changed from SU $(\triangle \mathrm{FPG}=4 \mathrm{mg} / \mathrm{dL}, P=0.776)$, the add-on to SU group $(\triangle \mathrm{FPG}=-5.1 \mathrm{mg} / \mathrm{dL}, P=1.0)$, the add-on to MET group $(\triangle \mathrm{FPG}=2.36 \mathrm{mg} / \mathrm{dL}, P=0.74)$, or the group changed from TZD ( $\triangle \mathrm{FPG}=-7.2 \mathrm{mg} / \mathrm{dL}, P=0.192$ ) (Table 2, Fig. 2).

Side effects were reported in eight of the 99 patients. One patient showed symptoms of hypoglycemia, one patient had an increase in body weight, five patients showed signs of indigestion, abdominal discomfort and gastrointestinal problems, and one patient reported problems with facial swelling. All patients who complained of gastrointestinal symptoms were being treated with MET combination therapy. There were no serious adverse effects associated with SITA.

\section{Analysis on the treatment failure group}

SITA treatment failure was experienced by 12 patients (five males, seven females): four patients changed from or added to insulin treatment, four patients added to MET treatment, one on the patient had initial combination of SITA with MET, one patient switching from SU, and one patient changed from TZD.

Compared to 87 patients in the treatment maintenance group, the diabetes duration of the treatment failure group was longer (7.6 vs. 2.8 year, $P=0.008$ ), the $\mathrm{HbA} 1 \mathrm{c}$ level at visit 1 was higher $(8.6 \%$ vs. $7.0 \%, P=0.001)$ and the FPG was higher (193 vs. $151 \mathrm{mg} / \mathrm{dL}, P=0.003)$. Age, gender, BMI, fasting insulin, and C-peptide level before taking the anti-diabetic drugs, history of hypertension, and hyperlipidemia were not significantly different between the treatment failure and maintenance group (Table 3).

\section{Subanalysis on tertiles of $\Delta \mathrm{HbAlc}$ in the treatment maintenance group}

During treatment, the $\Delta \mathrm{HbA} 1 \mathrm{c}$ in the 87 patients who continued treatment were categorized into tertiles. Good response group (tertile 3 of $\triangle \mathrm{HbA} 1 \mathrm{c}$ ) had a large improvement in blood glucose level, and low response group (tertile 1 of $\Delta \mathrm{HbA} 1 \mathrm{c}$ ) experienced a small improvement in blood glucose level. Compared to low response group, the $\mathrm{HbA1c}$ level at visit 1 of good response group was higher $(7.5 \%$ vs. $6.6 \%, P<0.001)$ and the duration of diabetes was shorter (2.0 vs. 4.0 year, $P=0.009$ ); however, age, fasting glucose level, BMI, fasting insulin level, and C-peptide level were not significantly different between 
Table 3. Baseline demographic and clinical differences between the treatment failure group and the treatment maintenance group during observation period

\begin{tabular}{|c|c|c|c|}
\hline Variable & Treatment failure group & Treatment maintenance group & $P$ value \\
\hline No. (\%) & $12(12.1)$ & $87(87.9)$ & \\
\hline Age, yr & $54.5(42.5,54.5)$ & $55.0(47.0,62.0)$ & 0.923 \\
\hline Female, $n(\%)$ & $7(58.3)$ & $56(64.4)$ & 0.684 \\
\hline Duration of T2DM, yr & $7.6(2.5,12.4)$ & $2.8(1.3,5.0)$ & $0.008^{\mathrm{a}}$ \\
\hline HbAlc, $\%$ & $8.6(7.5,10.1)$ & $7.0(6.6,7.6)$ & $0.001^{\mathrm{a}}$ \\
\hline FPG, mg/dL & $193(152,234)$ & $145(126,157)$ & $0.003^{a}$ \\
\hline $\mathrm{BMI}, \mathrm{kg} / \mathrm{m}^{2}$ & $26.3(20.3,32.9)$ & $25.4(23.1,27.6)$ & 0.760 \\
\hline Fasting insulin, $\mu \mathrm{IU} / \mathrm{mL}$ & $9.3(3.3,14.1)$ & $11.3(8.4,13.7)$ & 0.367 \\
\hline Fasting C-peptide, ng/mL & $2.4(1.3,4.0)$ & $3.1(2.4,3.7)$ & 0.382 \\
\hline Glycemic medication Hx., $n(\%)$ & $10(83.3)$ & $66(75.9)$ & 0.566 \\
\hline Anti-hypertensive agent, $n(\%)$ & $6(50.0)$ & $41(47.1)$ & 0.852 \\
\hline Anti-lipid agent, $n(\%)$ & $5(41.7)$ & $51(58.6)$ & 0.267 \\
\hline Smoking, $n(\%)$ & $3(25.0)$ & $19(22.1)$ & 0.821 \\
\hline
\end{tabular}

Data are presented as median (25\% confidence interval [CI], 75\% CI) or number (\%).

T2DM, type 2 diabetes mellitus; BMI, body mass index.

${ }^{a}$ Statistical significances were tested by $\chi^{2-}$-test for categorical variables and Mann-Whitney test for continuous variables.

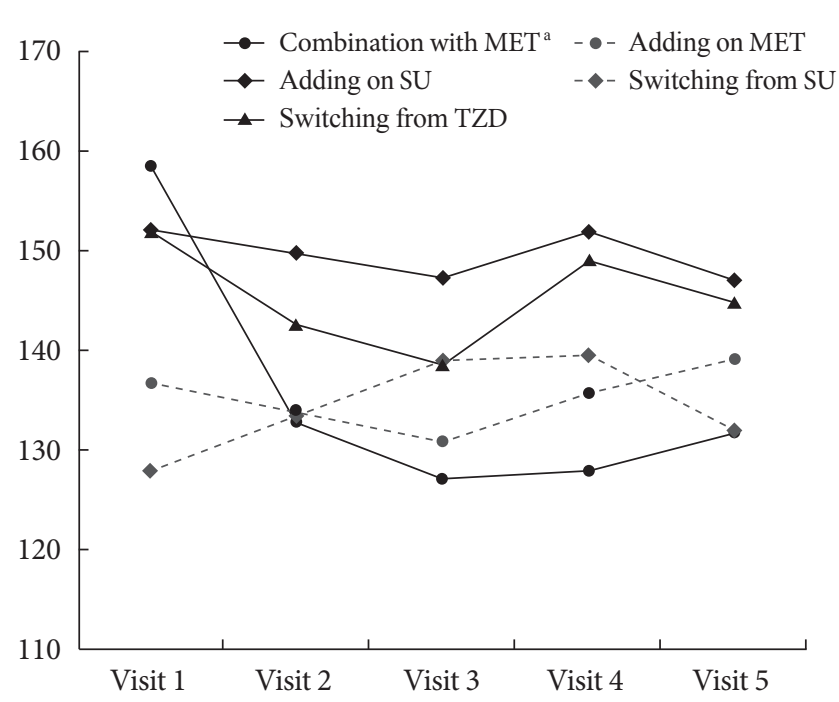

Fig. 2. Fasting plasma glucose change over time. MET, metformin; SU, Sulfonylurea; TZD, thiazolidinedione. ${ }^{a}$ Denotes significant reduction by according to the Wilcoxon Signed Rank test.

the two subgroups (Table 4).

\section{DISCUSSION}

In this study, the treatment outcomes of SITA were analyzed at one university hospital for an average duration of ten months.
The patients were divided into groups based on the classification of treatment regimens and were retrospectively reviewed. Significant improvements in $\mathrm{HbA1c}$ and blood glucose levels were observed after a few months in the initial coadministration of SITA with MET group, the add-on to MET or SU groups and in the group switched from TZD. The efficacy of the SITA showed a similar effect as that of the SU, usually the minimum amount of commercial units.

Although there were many complaints of gastrointestinal discomfort, all of them were from the group coadministrated with MET. Among those who complained, no clinically significant adverse effects were observed. Compared to the treatment maintenance group, the duration of diabetes of the treatment failure group was longer and the HbAlc and FPG were higher. However, the age, gender, BMI, fasting insulin, fasting C-peptide, antihypertensive medication, antihyperlipidemia medication history, and smoking history were not significantly different in these groups.

After the recent development of drugs that increase the levels of the incretin hormones GLP-1 and GIP, it was found that commercialized DPP IV-inhibitor prolonged and enhanced incretin hormone activity. As a result of these drugs, insulin secretion from pancreatic $\beta$ cells is stimulated based on blood sugar level; glucagon secretion from pancreatic $\alpha$-cells is suppressed to manage blood glucose, pancreatic cell dysfunction 
Table 4. Baseline demographic and clinical differences of treatment maintenance group according to $\mathrm{HbA} 1 \mathrm{c} c h a n g e(\Delta \mathrm{HbA} 1 \mathrm{c}$, $\mathrm{HbA1c}$ at visit $1-\mathrm{HbA1c}$ at visit 5) tertiles, excluding 2nd tertile group

\begin{tabular}{lccc}
\hline Variable & 1st tertile $(\Delta$ HbAlc $\leq 0.2 \%)$ & 3rd tertile $(\Delta$ HbAlc $>0.7 \%)$ & $P$ value \\
\hline No. $(\%)$ & $29(33.3)$ & $30(34.5)$ & $22(73.0)$ \\
Female, $n(\%)$ & $15(52.0)$ & $55.0(46.0,65.0)$ & 0.198 \\
Age, yr & $56.0(48.0,60.0)$ & $2.0(0.9,3.0)$ & 0.525 \\
Duration of T2DM, yr & $4.0(2.5,7.4)$ & $7.5(7.1,8.2)$ & $0.009^{\mathrm{a}}$ \\
HbA1c, $\%$ & $6.6(6.2,6.9)$ & $151(137,170)$ & $<0.001^{\mathrm{a}}$ \\
FPG, $\mathrm{mg} / \mathrm{dL}$ & $131(118,151)$ & $25.2(23.8,28.6)$ & 0.082 \\
BMI, $\mathrm{kg} / \mathrm{m}^{2}$ & $26.7(23.9,29.1)$ & $10.4(8.4,13.4)$ & 0.861 \\
Fasting insulin, $\mu \mathrm{IU} / \mathrm{mL}$ & $12.3(8.7,16.8)$ & $3.4(2.8,3.9)$ & 0.791 \\
Fasting C-peptide, $\mathrm{ng} / \mathrm{mL}$ & $2.8(2.3,3.7)$ & 0.762 \\
\hline
\end{tabular}

Data are presented as median (25\% confidence interval [CI], 75\% CI) or number (\%).

${ }^{a}$ Statistical significances were tested by Kruskal-Wallis and Bonferroni post-hoc analysis.

is prevented, and hypoglycemia and weight gain are rare $[4,11,12]$.

SITA $\left(\right.$ Januvia $^{\circledR}$ ) is the first DPP IV-inhibitor that has been licensed for use in type 2 diabetes patients; It has been reported to not affect the pharmacokinetics of other oral diabetes drugs such as MET, SU, and rosiglitazone [10,13]. The validity and reliability of SITA have been demonstrated in type 2 diabetes patients because blood glucose level is improved and side effects from SU or insulin-like treatment drugs such as hypoglycemia and weight gain are very uncommon. FDA approved the use of SITA in type 2 diabetes and drug indications are as follows: SITA monotherapy, combination therapy with MET, dual add-on therapy to SU, MET, TZD, triple oral therapy with MET, SU/TZD, and add-on to insulin. Domestically, however, only the add-on to MET has been acknowledged for uncontrolled type 2 diabetic patients.

Several randomized double-blind clinical trials have evaluated the efficacy of oral sitagliptin in type 2 diabetic patients with $\mathrm{HbAlc}$ level ranged from $6.5-8 \%$ to $10-12 \%$. Initial coadministration therapy of SITA with MET significantly lowered HbA1c, FPG and two-hour postprandial blood glucose levels more than did MET monotherapy after 24 weeks of treatment, and maintained the effect for 54 to 104 weeks [14-16]. When SITA was added to MET, the reductions in HbAlc and FPG were sustained during an 18- to 24-week observation period [17-19], and when added to SU, improvements in blood glucose were maintained for 24 weeks [20]. Additionally, when $100 \mathrm{mg}$ of both SITA and MET were combined, there was no comparative difference in the level of reduction in HbAlc level between 52 weeks of MET and $5 \mathrm{mg}$ glipizide [21] or 18 weeks of an 8-mg rosiglitazone and MET combination therapy [19]. In the present study, significant improvements in $\mathrm{HbAlc}$ level were found in every group except the group switched from SU. Two to three months after the initial treatment, the significant decrease in $\mathrm{HbAlc}$ level plateaued and was maintained for ten months. The group switched from SU was administered an average dosage of $1.8 \mathrm{mg}$ glimepiride and an average dosage of $30 \mathrm{mg}$ gliclazide $\mathrm{MR}$.

Unlike HbA1c, FPG showed an immediate improvement only in the initial MET and SITA combination group. However, the values of FPG in other four groups were less recorded and the standard deviation of FPG was higher than the standard deviation of the HbAlc. These results indicate a limitation to our retrospective study.

The average body weight change in the patients in the group switched from TZD during the observation period was $1.1 \mathrm{~kg}$, but it was not significant $(n=14, P=0.124)$. The 18-week study by Scott et al. [19] demonstrated that, while the addition of TZD to MET gained an average of $1.5 \mathrm{~kg}$, the addition of SITA to MET lost an average of $0.4 \mathrm{~kg}$, a $1.9-\mathrm{kg}$ difference between the two groups. Therefore, SITA can be used as an alternative to avoid the weight gain associated with TZD.

In the meta-analysis of SITA, the risk of hypoglycemia is associated with the combination with SU or insulin treatment and gastrointestinal side effects is associated with MET [20,22,23]. In the present study, one patient who reported having hypoglycemia had previously taken $\mathrm{SU}$, and the five patients who had reported gastrointestinal side effects were all taking MET; 
the side effects of SITA monotherapy could not be determined.

The duratin of diabetes $(P=0.008), \mathrm{HbAlc}(P=0.001)$ and FPG $(P=0.003)$ in the treatment failure group were significantly higher than those of the treatment maintenance group (Table 3). However, only a small number of patients were classified into the failure group, and more domestic participants are needed for further analysis.

When $\triangle \mathrm{HbAlc}$ of the treatment maintenance group were divided into three parts and analyzed, the low response group had a longer diabetes duration $(P=0.009)$ as well as a lower initial HbA1c level $(P<0.001)$ (Table 4$)$. However, the low response group did not mean treatment failure and our results suggest that the efficacy of sitaglitin therapy is noninferior to that of other common diabetes drugs such as SU. Additionally, the grehlin hormone and the parasympathetic nervous system are involved in the regulation of GLP-1 $[24,25]$ and genetic polymorphisms of GLP-1 receptors have been reported [26]. Further understanding the individual responses to fats and carbohydrates and GLP-1 receptor will help predict non- or less-responders to SITA.

This study had several limitations. First, we only selected subjects at a single university hospital and the number of available participants in each group was small due to the selection criteria and classification. Second, the retrospective approach lost some data of clinical and biochemical parameters. Third, the preservation of pancreatic $\beta$-cell function from SITA administration could not be confirmed clinically since oral glucose tolerance tests were not usually performed after administration of SITA. However, according to most of the other reports, significant improvements in the homeostasis model of assessment of $\beta$-cell function (HOMA- $\beta$ ), the proinsulin-toinsulin ratio, and the insulinogenic index were reported [10, $14,17,18,23]$. SITA was found to have no effect on insulin resistance or sensitivity as reflected by HOMA-IR and the quantitative insulin sensitivity check index (QUICKI) [18,20,27]; on the other hand, some reports showed significant improvements in insulin resistance or sensitivity [17,28].

In summary, SITA is efficient for glycemic controls in the cases of the initial coadministration with MET, the add-on therapy to MET or SU and administration switched from TZD or SU. It is also relatively safe over an average of ten months in Korean type 2 diabetes. However, well-designed, prospective and long-term studies are needed to understand the treatment failure or response of SITA.

\section{CONFLICTS OF INTEREST}

No potential conflict of interest relevant to this article was reported.

\section{REFERENCES}

1. Yoon KH. Pathogenesis of type 2 diabetes in Korea. J Korean Diabetes Assoc 2000;24:397-403.

2. Shichiri M, Kishikawa H, Ohkubo Y, Wake N. Long-term results of the Kumamoto study on optimal diabetes control in type 2 diabetic patients. Diabetes Care 2000;23 Suppl 2:B21-9.

3. Turner RC, Cull CA, Frighi V, Holman RR. Glycemic control with diet, sulfonylurea, metformin, or insulin in patients with type 2 diabetes mellitus: progressive requirement for multiple therapies (UKPDS 49). UK Prospective Diabetes Study (UKPDS) Group. JAMA 1999;281:2005-12.

4. Herman GA, Bergman A, Stevens C, Kotey P, Yi B, Zhao P, Dietrich B, Golor G, Schrodter A, Keymeulen B, Lasseter KC, Kipnes MS, Snyder K, Hilliard D, Tanen M, Cilissen C, De Smet M, de Lepeleire I, Van Dyck K, Wang AQ, Zeng W, Davies MJ, Tanaka W, Holst JJ, Deacon CF, Gottesdiener KM, Wagner JA. Effect of single oral doses of sitagliptin, a dipeptidyl peptidase-4 inhibitor, on incretin and plasma glucose levels after an oral glucose tolerance test in patients with type 2 diabetes. J Clin Endocrinol Metab 2006;91:4612-9.

5. Farilla L, Hui H, Bertolotto C, Kang E, Bulotta A, Di Mario U, Perfetti R. Glucagon-like peptide-1 promotes islet cell growth and inhibits apoptosis in Zucker diabetic rats. Endocrinology 2002;143:4397-408.

6. Farilla L, Bulotta A, Hirshberg B, Li Calzi S, Khoury N, Noushmehr H, Bertolotto C, Di Mario U, Harlan DM, Perfetti R. Glucagon-like peptide 1 inhibits cell apoptosis and improves glucose responsiveness of freshly isolated human islets. Endocrinology 2003;144:5149-58.

7. Toft-Nielsen MB, Damholt MB, Madsbad S, Hilsted LM, Hughes TE, Michelsen BK, Holst JJ. Determinants of the impaired secretion of glucagon-like peptide- 1 in type 2 diabetic patients. J Clin Endocrinol Metab 2001;86:3717-23.

8. Nauck MA, Heimesaat MM, Orskov C, Holst JJ, Ebert R, Creutzfeldt W. Preserved incretin activity of glucagon-like peptide 1 [7-36 amide] but not of synthetic human gastric inhibitory polypeptide in patients with type-2 diabetes mellitus. J Clin Invest 1993;91:301-7.

9. Kim MH, Lee MK. Incretins and pancreatic beta cells: use of 
glucagon-like peptide-1 and glucose-dependent insulinotropic polypeptide to cure type 2 diabetes mellitus. Korean Diabetes J 2010;34:2-9.

10. Dhillon S. Sitagliptin: a review of its use in the management of type 2 diabetes mellitus. Drugs 2010;70:489-512.

11. Rosenstock J, Zinman B. Dipeptidyl peptidase-4 inhibitors and the management of type 2 diabetes mellitus. Curr Opin Endocrinol Diabetes Obes 2007;14:98-107.

12. Ahren B. Dipeptidyl peptidase-4 inhibitors: clinical data and clinical implications. Diabetes Care 2007;30:1344-50.

13. Mistry GC, Bergman AJ, Zheng W, Hreniuk D, Zinny MA, Gottesdiener KM, Wagner JA, Herman GA, Ruddy M. Sitagliptin, an dipeptidyl peptidase-4 inhibitor, does not alter the pharmacokinetics of the sulphonylurea, glyburide, in healthy subjects. Br J Clin Pharmacol 2008;66:36-42.

14. Goldstein BJ, Feinglos MN, Lunceford JK, Johnson J, WilliamsHerman DE; Sitagliptin 036 Study Group. Effect of initial combination therapy with sitagliptin, a dipeptidyl peptidase- 4 inhibitor, and metformin on glycemic control in patients with type 2 diabetes. Diabetes Care 2007;30:1979-87.

15. Williams-Herman D, Johnson J, Teng R, Luo E, Davies MJ, Kaufman KD, Goldstein BJ, Amatruda JM. Efficacy and safety of initial combination therapy with sitagliptin and metformin in patients with type 2 diabetes: a 54-week study. Curr Med Res Opin 2009;25:569-83.

16. Qi DS, Teng R, Jiang M, Davies MJ, Kaufman KD, Amatruda JM, Williams-Herman D. Two-year treatment with sitagliptin and initial combination therapy of sitagliptin and metformin provides substantial and durable glycaemic control in patients with type 2 diabetes. Diabetologia 2008;51(Suppl 1):S36.

17. Charbonnel B, Karasik A, Liu J, Wu M, Meininger G; Sitagliptin Study 020 Group. Efficacy and safety of the dipeptidyl peptidase-4 inhibitor sitagliptin added to ongoing metformin therapy in patients with type 2 diabetes inadequately controlled with metformin alone. Diabetes Care 2006;29:2638-43.

18. Raz I, Chen Y, Wu M, Hussain S, Kaufman KD, Amatruda JM, Langdon RB, Stein PP, Alba M. Efficacy and safety of sitagliptin added to ongoing metformin therapy in patients with type 2 diabetes. Curr Med Res Opin 2008;24:537-50.

19. Scott R, Loeys T, Davies MJ, Engel SS; Sitagliptin Study 801 Group. Efficacy and safety of sitagliptin when added to ongo- ing metformin therapy in patients with type 2 diabetes. Diabetes Obes Metab 2008;10:959-69.

20. Hermansen K, Kipnes M, Luo E, Fanurik D, Khatami H, Stein P; Sitagliptin Study 035 Group. Efficacy and safety of the dipeptidyl peptidase- 4 inhibitor, sitagliptin, in patients with type 2 diabetes mellitus inadequately controlled on glimepiride alone or on glimepiride and metformin. Diabetes Obes Metab 2007;9:733-45.

21. Nauck MA, Meininger G, Sheng D, Terranella L, Stein PP; Sitagliptin Study 024 Group. Efficacy and safety of the dipeptidyl peptidase-4 inhibitor, sitagliptin, compared with the sulfonylurea, glipizide, in patients with type 2 diabetes inadequately controlled on metformin alone: a randomized, double-blind, non-inferiority trial. Diabetes Obes Metab 2007;9:194-205.

22. Amori RE, Lau J, Pittas AG. Efficacy and safety of incretin therapy in type 2 diabetes: systematic review and meta-analysis. JAMA 2007;298:194-206.

23. Vilsboll T, Rosenstock J, Yki-Jarvinen H, Cefalu WT, Chen Y, Luo E, Musser B, Andryuk PJ, Ling Y, Kaufman KD, Amatruda JM, Engel SS, Katz L. Efficacy and safety of sitagliptin when added to insulin therapy in patients with type 2 diabetes. Diabetes Obes Metab 2010;12:167-77.

24. Inui A, Asakawa A, Bowers CY, Mantovani G, Laviano A, Meguid MM, Fujimiya M. Ghrelin, appetite, and gastric motility: the emerging role of the stomach as an endocrine organ. FASEB J 2004;18:439-56.

25. Brubaker PL, Anini Y. Direct and indirect mechanisms regulating secretion of glucagon-like peptide-1 and glucagon-like peptide-2. Can J Physiol Pharmacol 2003;81:1005-12.

26. Beinborn M, Worrall CI, McBride EW, Kopin AS. A human glucagon-like peptide-1 receptor polymorphism results in reduced agonist responsiveness. Regul Pept 2005;130:1-6.

27. Aschner P, Kipnes MS, Lunceford JK, Sanchez M, Mickel C, Williams-Herman DE; Sitagliptin Study 021 Group. Effect of the dipeptidyl peptidase-4 inhibitor sitagliptin as monotherapy on glycemic control in patients with type 2 diabetes. Diabetes Care 2006;29:2632-7.

28. Mohan V, Yang W, Son HY, Xu L, Noble L, Langdon RB, Amatruda JM, Stein PP, Kaufman KD. Efficacy and safety of sitagliptin in the treatment of patients with type 2 diabetes in China, India, and Korea. Diabetes Res Clin Pract 2009;83:106-16. 